\title{
INFÂNCIA E ESCOLA NOVA: UM OLHAR CRÍTICO SOBRE A CONTRIBUIÇÃO DE JOHN DEWEY PARA A CONSOLIDAÇÃO DO PENSAMENTO LIBERAL NA EDUCAÇÃ ${ }^{1}$
}

Marco Aurélio Gomes de Oliveira Universidade Federal do Tocantins/Campus Tocantinópolis - UFT

Armindo Quillici Neto Universidade Federal de Uberlândia/Campus Ituiutaba - UFU

\section{RESUMO}

Este artigo tem como objetivo discutir a concepção de infância em John Dewey e a relação do seu projeto de renovação pedagógica e como os conceitos (democracia, liberdade e experiência) estão associados para a formação de um novo homem, adaptado ao sistema capitalista. Nesse sentido, este artigo aborda a temática da infância e da educação numa perspectiva histórica, isto é, levamos em consideração que a produção das ideias e pensamentos estão condicionados pelos meios de produção de seu tempo histórico. Portanto, a infância, na perspectiva deweyana, é pensada a partir da relação da experiência com o meio social e de sua potencialidade de mudança que vislumbra a concretização de uma sociedade democrática, algo que contribuiu para o fortalecimento do pensamento liberal na educação.

Palavras-Chave: Infância; Escola Nova; Educação e filosofia; John Dewey.

\section{CHILDHOOD AND THE NEW SCHOOL: A CRITIC VIEW OVER THE CONTRIBUTION OF JOHN DEWEY TO THE CONSOLIDATION OF THE LIBERAL THOUGHT IN EDUCATION}

\begin{abstract}
The objective of this article is to discuss the conception of childhood in John Dewey`s project of renewing pedagogy and, how the concepts (democracy, freedom and experience) are associated to make up a new man who is adapted to the capitalist system. This way, this article brings up the themes childhood and education in a historical perspective, that is, it is taken into consideration that the production of ideas and thought are conditioned to production methods in its historical time. Therefore, in Deweyan perspective, childhood is thought considering the relation between experience and the social environment and its changing potentiality that aims to make a democratic society come true, which contributes to the strengthening of the liberal thinking in education.
\end{abstract}

Keywords: Childhood; New School; Education and Philosophy; John Dewey

\section{A liberdade e a democracia em John Dewey: princípios fundamentais para uma nova infância}

O contexto histórico revela-nos que John Dewey (1859-1952) viveu num período de ascensão dos Estados Unidos, frente ao mundo, graças ao processo acelerado da industrialização e das condições materiais que possibilitou um rápido crescimento populacional. Segundo Hobsbawm (1977, p. 155), o olhar encantador do mundo para os 
Estados Unidos se dava pela riqueza produzida naquele país e pela forma como o povo estadunidense encarava o capitalismo, a exacerbação da individualidade fundada no princípio democrático, herdado dos patriarcas da América $^{2}$, possibilitava $\mathrm{o}$ empreendimento de grandes projeções.

Os Estados Unidos, vistos como o novo mundo, a partir da segunda metade do século XIX, atraíram milhares de imigrantes e capitalistas europeus e de outras partes do mundo com um único objetivo: fazer dinheiro e viver bem. Os princípios liberais tinham sido bem incorporados pelos estadunidenses, que entregavam sua vida ao trabalho como meio de produzir sua riqueza, pois, acima de tudo, conforme Hobsbawm (1977)

[...] estavam imbuídos [...] pelo imperativo capitalista da acumulação. As oportunidades eram realmente colossais para homens preparados para seguir a lógica da obtenção do lucro em lugar da lógica de viver, e que possuíam competência suficiente, energia, rudeza e ambição. As distrações eram mínimas. Não havia uma velha nobreza para seduzir os homens com títulos, e nem o exemplo tentador da vida descontraída de uma aristocracia agrária. A política era antes algo para se comprar do que para se praticar, exceto, evidentemente, como outro meio de fazer dinheiro. (HOBSBAWM, 1977, p. 163).

Portanto, numa sociedade capitalista, que vivia seu auge de produção e consumo, a educação era um importante instrumento para formação da população e não havia melhor caminho do que ter como princípio um modelo fundamentado no aprender fazendo learning by doing, no qual a liberdade dos educandos era estimulada para soluções das situações problema do cotidiano escolar e social, com a utilização de procedimentos científicos, cabendo ao mestre a condução desse processo educativo. (MANACORDA, 2010, p. 372).

John Dewey, um produto histórico do seu contexto ${ }^{3}$, concebe a educação como um processo contínuo de aprendizagem em que o educando deve experimentar e avaliar as condições de sua aprendizagem, dessa forma, o lema - aprender fazendo - retrata a natureza filosófica de sua teoria educacional. É importante ressaltar a contribuição do filósofo na discussão sobre a escola e o trabalho e a relação dos princípios pedagógicos com os princípios sociais.

Dewey (1979) acredita que a escola é o espaço mais apropriado para realizar as experiências educativas das crianças e aponta a necessidade de um planejamento pedagógico que vise a uma integração com a sociedade, pois "[...] aprender com a própria vida e tornar tais as condições da vida em que todos aprendam com o processo de viver, é o mais belo produto da eficiência escolar". (DEWEY, 1979, p. 55).

A perspectiva deweyana vislumbra uma sociedade harmonizada a partir da educação científica para todos e tem, na atividade infantil, o elemento que possibilita formar um homem que saiba lidar com situações diversas no cotidiano, que participe coletivamente das decisões e valorize sua capacidade individual, pois essa característica o diferencia dos demais, sendo mais reconhecido aquele que consegue usar sua inteligência a serviço de uma finalidade, seja ela educativa ou produtiva.

Esse ponto, para Manacorda (2010), marca a diferença e a limitação da concepção de mundo, de sociedade e de homem em Dewey para um projeto de transformação social, defendido por Marx e Engels, pois o seu lema "[...] learning by doing, o aprendendo fazendo, é o centro da unidade de instrução e trabalho [...] não é a mesma unidade visada por Marx: é a adequação dinâmica da escola à vida produtiva real, dinâmica no sentido de que a escola pode ser chamada a colaborar para a mudança, mesmo que, acrescente, 
corrigindo a ilusão pedagógica inicial [...]”. (MANACORDA, 2010, p. 384, grifo do autor).

A filiação filosófica ao pragmatismo possibilita ao filósofo compreender que a concretização da mudança pedagógica não se dá simplesmente por meios práticos ou teóricos, mas, sim, na compreensão geral do papel da filosofia como ponto de referência para a direção que deseja evoluir na educação.

A reconstrução da filosofia, a da educação e dos ideais e métodos sociais, caminham, assim, de mãos dadas. Se for verdade que existe, nos tempos atuais, uma necessidade especial de reconstrução educativa, se essa necessidade torna urgente uma revisão das ideias básicas dos sistemas filosóficos tradicionais, é devido à completa mudança da vida social, paralela aos progressos da ciência, à revolução industrial e ao desenvolvimento da democracia. Não se podem efetuar essas mudanças na vida prática sem uma reforma educativa de acordo com elas, sem levar os homens a perguntar-se que ideias e ideais existem implícitos nessas transformações sociais, e que mudanças elas requerem nas ideias e ideais herdados das velhas e dessemelhantes culturas. (DEWEY, 1979, p. 364$365)$.

Dessa forma, fica evidente o papel fundamental que a educação exercerá para o fortalecimento do novo sistema, e de uma filosofia que a sustente e oriente com princípios que possibilitem uma constante avaliação de seus propósitos. Sendo assim, a mudança do sistema social buscou associar-se a várias esferas para a difusão e a incorporação de seus ideais básicos, e a esfera da educação é uma das mais cobiçadas pelo sistema.

Segundo Hobsbawm (1977), uma característica do contexto educacional estadunidense se relaciona diretamente com essa concepção filosófica, pois a compreensão de progresso científico não está necessariamente amarrada à ideia de originalidade, mas, sim, na "[...] capacidade de compreender e manipular ciência: desenvolvimento mais do que pesquisa". Logo, a preocupação era formar "[...] em massa, engenheiros de nível adequado ao invés de produzir uns poucos superiormente inteligentes e de grande cultura [...]". (HOBSBAWM, 1977, p. 63).

A associação de ciência e educação recebe, concomitantemente, influências do campo econômico e político, como tratamos anteriormente, bem como do pensamento pragmatista, iniciado por Charles Peirce e popularizado por William James e pelo próprio Dewey. No sentido de esclarecer nossa afirmação sobre a relação - ciência e educação existente na educação estadunidense, o trecho a seguir, do livro Experiência e Educação, escrito por Dewey em 1938, mostra o quão é essencial tal parceria para efetivação de uma proposta educacional.

O sentido da ênfase que ponho no método científico tem pouco a ver com técnicas especializadas. O que desejei dizer é que o método científico é o único meio autêntico sob o nosso comando para obter a compreensão da real significação das experiências de todos os dias, no mundo em que vivemos. O método científico provê um modelo operante e eficaz do modo pelo qual e das condições sob as quais podemos utilizar experiências para delas extrairmos luzes e conhecimentos que nos guiem para frente e para fora em nosso mundo em expansão. (DEWEY, 1976, p. 93).

O trecho acima reafirma a incorporação dos princípios do pragmatismo. Charles Peirce (1839-1914) desenvolveu uma lógica de raciocínio que busca superar a dicotomia existente entre a lógica dedutiva -, que tem no campo abstrato e geral sua formulação 
central -, e a lógica indutiva -, que parte única e exclusivamente da experiência sobre o objeto/matéria para formular um raciocínio -, para uma lógica abdutiva, que propõe uma associação da teoria com a experimentação, guiadas por um propósito prático.

De acordo com Peirce (2008), a filosofia pragmática cumpre uma função de produzir novos conhecimentos a partir de uma necessidade prática, isto é, o conhecimento produzido em sintonia com as demandas sociais. Para o autor, "[...] a Abdução simplesmente sugere que alguma coisa pode ser. Sua única justificativa é que, a partir de suas sugestões, a dedução pode extrair uma predição que pode ser verificada por indução, e isso, se é que nos é dado aprender algo ou compreender os fenômenos, deve ser realizado através da abdução". (PEIRCE, 2008, p. 220). Portanto, a abdução é um conceito chave para compreendermos a corrente filosófica do pragmatismo e, concomitantemente, como se apresenta no pensamento deweyano.

A apropriação dos princípios pragmatista, na teoria deweyana, está relacionada com sua visão de ciência e produção do conhecimento, fundamentada na lógica utilitarista do uso da inteligência para o bem social em prol do progresso científico e tecnológico. Para Dewey (1979), a ciência proporciona "[...] que todas as concepções e afirmações sejam de tal natureza, que umas continuem outras e conduzam a outras. [...] Esta dupla relação de conduzir para alguma coisa e confirmar alguma coisa é o que significamos com os termos lógico e racional". (DEWEY, 1979, p. 210).

Entretanto consideramos aqui um dos pontos contraditórios da teoria educacional do filósofo americano, pois a relação ciência $X$ demanda social é determinada pelas relações de produção que regem o sistema capitalista, e não apresenta uma preocupação em desenvolver uma formação humana em sua plenitude, mas, sim, a criação de um sujeito alienado que não reconheça no seu trabalho a fonte de sua existência material, isto é, o homem passa a ser encarado como uma máquina viva, que serve apenas para alimentar e produzir a riqueza material do capital.

Para Marx e Engels (2010), a industrialização moderna transformou a ciência num conjunto de conhecimentos técnicos que visam ao aperfeiçoamento do trabalhador e das forças produtivas com o único propósito de aumentar sua riqueza material. Nessa perspectiva, o trabalhador perde o controle e sua autonomia na produção científica, pois não cabe a ele decidir o que pesquisar e como pesquisar, pois "[...] as formas multifárias, aparentemente desconexas e petrificadas do processo social de produção, se decompõem em aplicações da ciência conscientemente planejadas e sistematicamente especializadas segundo o efeito útil requerido". (MARX e ENGELS, 2010, p. 77).

Portanto, é importante deixar claro que a preocupação deweyana de socialização do conhecimento está direcionada para uma classe, para um modelo social, ou seja, a burguesia, e para o fortalecimento das relações capitalistas, que, na sua perspectiva, avançaram a patamares impressionantes graças ao desenvolvimento industrial.

As propostas de Dewey eram pensadas com base nas dificuldades e contradições do modelo social vigente, consideradas por este autor como decorrentes de um modelo liberal ultrapassado e inadequado que confundiu capitalismo com liberalismo. O problema a ser superado não era o modo de produção vigente, mas a forma de pensar e agir nele existente. Se mudassem o sentimento e o pensamento dos homens, as crises presentes se resolveriam. Desse modo, as suas propostas visavam conciliar os diversos interesses das classes, mas a sua manutenção de uma forma mais justa e mais humana. Para ele, era possível uma convivência pacífica entre as diferentes classes sociais. (GALIANI, 2009, p. 137). 
Ressaltamos essa contradição no pensamento deweyano sobre ciência e demanda social, por acreditar que essa relação está associada diretamente à sua concepção de educação e sociedade e demais princípios fundamentais de sua teoria, como, por exemplo, liberdade e democracia, que nos dá uma visão global sobre sua concepção de infância.

Para Dewey (1979, p. 13), a liberdade e democracia são princípios que devem ser almejados para a realização de uma sociedade moderna. É interessante perceber que essa valorização da prática democrática e do exercício da liberdade individual tem suas raízes nos fundadores da América, em especial, a concepção política de Thomas Jefferson (17431826), que trouxe uma contribuição fundamental para a formação do espírito de liberdade do povo estadunidense nos séculos XVIII e XIX.

Em sua obra Liberdade e Cultura, escrita em 1939, Dewey apresenta uma discussão sobre o papel do sujeito, da liberdade e da cultura para formação de uma sociedade democrática. Nessa obra, o autor destaca o papel relevante exercido pelos fundadores da América, homens que acreditavam na liberdade individual e, acima de tudo, no poder que ela tem de transformar uma nação.

Em todo país em que o homem tem liberdade para pensar e falar surgem divergências de opinião sobre diferença de percepção e imperfeição da razão; mas essas divergências, quando permitidas como neste país, para purificar-se pelo livre debate, são apenas nuvens passageiras que se estendem transitoriamente pelo país e deixam nosso horizonte mais brilhante e mais sereno. Esse amor pela ordem e obediência às leis, que caracterizam tão extraordinariamente os cidadãos dos Estados Unidos, constitui penhores seguros da tranqüilidade interna; e o direito de voto eletivo, se preservado como a arca de nossa segurança, dissipará pacificamente todas as combinações de subverter-se uma Constituição ditada pela sabedoria e apoiada na vontade do povo. Essa vontade é o único fundamento legítimo de qualquer governo, e proteger sua livre manifestação deve ser nosso primeiro objetivo. (JEFFERSON, 1964, p. 76).

Dewey corrobora Jefferson $(1964$, p. 52) a ideia de que a liberdade de um povo esteja associada a sua participação política nos rumos do país. Quando o autor discute sobre as condições para o exercício livre da cidadania e da liberdade, é interessante nos atentarmos para uma questão crucial que revela o propósito de uma (re) novação na ideia sobre infância. O caráter liberal ${ }^{4}$ da (re) novação é essencial para entendermos a profundidade da proposta, pois sua intenção e referências ideológicas almejavam promover uma readaptação dos sujeitos à nova ordem mundial e não uma transformação social que interferisse na relação de produção no mundo do trabalho (DEWEY, 1953, p. 94).

Portanto, temos que compreender que sua noção de liberdade, democracia $e$ participação social está comprometida com uma visão de mundo burguês, que idealiza uma sociedade igualitária sem a necessidade de mexer em sua estrutura social de forma drástica, ou seja, que abale a ordem social.

Segundo Marx (2004, p. 81-82), o discurso capitalista de liberdade, democracia e participação social acoberta a realidade concreta, pois ela está determinada pelas condições desiguais de produção, e a privação dos meios de produção por parte do trabalhador faz com que seu trabalho, algo que o tornaria humano, no sistema capitalista, o transforma numa máquina que cria mercadoria e, ao mesmo tempo, se torna uma mercadoria por dispor somente de sua força de trabalho para sua sobrevivência ${ }^{5}$. 
Nesse sentido, convalidamos a tese de Hobsbawm (1977, p. 84) sobre o sistema capitalista em sua fase de consolidação, quando trata da "fantasia revolucionária" vestida pelo capital para afirmar seus princípios de igualdade, fraternidade e solidariedade entre os povos.

Não há dúvida de que os profetas burgueses de meados do século XIX olhavam para frente procurando um mundo único e mais ou menos padronizado, onde todos os governos teriam o conhecimento das verdades da economia política e do liberalismo, [...]. O máximo que se poderia então desejar é que estas nações comungassem o mesmo tipo de instituições, economia e credos. A unidade do mundo implicava sua divisão. O sistema mundial do capitalismo era uma estrutura de "economia nacionais" rivais. O triunfo mundial do liberalismo ficava na conversão de todos os povos, pelo menos os que eram vistos como “civilizados". (HOBSBAWM, 1977, p. 84).

Para Dewey (1953, p. 331), o fato de acreditar nos princípios do liberalismo só reafirma seu posicionamento político, pois o progresso social só é possível mediante liberdade individual em todas as esferas. Portanto, o liberalismo, na sua forma original na visão deweyana, deve ser ressignificado para atender às exigências da dinâmica do mundo do trabalho e, com isso, criar um espírito de solidariedade e comunhão entre os povos, independente das desigualdades econômicas e sociais.

Para Schilling (2004), Dewey expressa de forma clara o espírito norte-americano de ser, "[...] um ianque, um daqueles homens que, sozinhos, querem enfrentar o mundo e a natureza" e, dessa forma, não é admitida pelo filósofo americano uma submissão do homem ante à natureza e nem a sociedade, sobretudo, porque, ao longo da história, o homem foi submetido a vontades exteriores, ora por parte do Estado (polis grega), ora por parte da Igreja e ora por parte da sociedade (Iluminismo), é chegada a hora no contemporâneo "[...] do indivíduo ver-se inteiramente libertado daquele tipo de obrigações. Nenhuma canga seria imposta sobre sua pessoa, nem por parte do estado, nem pela sociedade". (SCHILLING, 2004, p. 119).

O ímpeto arrebatador descrito pelo autor sobre o homem americano é compreensível, se levarmos em conta que a visão de mundo, de homem e de sociedade que orienta suas ideias e práticas, está em sintonia com a essência do liberalismo, que, segundo Chaves (2007),

[...] sustenta-se no princípio fundamental de que quando o indivíduo, ao se associar com outros indivíduos, passa a viver em sociedade, a liberdade torna-se o seu bem supremo e, enquanto tal, tem preponderância sobre qualquer outro bem que possa ser imaginado. [...] Mas para nós, que vivemos em sociedade, a liberdade é essencial para e por nos preservar um espaço privado, inviolável, que não possa ser transgredido pelos nossos semelhantes. A função primordial do Estado é garantir a existência e a inviolabilidade desse espaço. [...] Por isso, o liberalismo luta para preservar esse espaço privado do indivíduo, seja contra a sua invasão por outros indivíduos, seja contra a sua restrição ou eliminação pelo Estado. Assim, a liberdade é, para o liberalismo, o bem supremo no contexto da relação do indivíduo com seus semelhantes na sociedade, e no contexto de sua relação com o Estado. (CHAVES, 2007, p. 07-08).

A liberdade, considerada como elemento central no pensamento burguês, é a forma de encarar o mundo e as relações sociais entre os homens, e não foi somente no período de consolidação da classe burguesa como classe dominante no século XIX que se tornou 
preponderante essa forma de agir e pensar. As raízes dessa compreensão filosófica sobre liberdade são datadas, historicamente, mesmo antes de sua elaboração mais sistematizada, ocorrida no século XVIII.

Enquanto doutrina, o liberalismo deve ser visto como a expressão mais desenvolvida da visão de mundo burguesa. Mas ela não surge do nada. Sua gênese deu-se no interior das lutas que a burguesia vinha travando contra a Igreja Católica e a nobreza no sentido de superar os "entraves feudais" postos ao desenvolvimento de seus negócios. No âmbito do discurso, essa classe alicerçava suas reivindicações nas liberdades individuais: liberdade de comerciar, liberdade de produzir, liberdade de crença, liberdade de trabalho etc. logo, o liberalismo, mesmo tendo sido formulado enquanto doutrina no século XVIII, tinha suas raízes fincadas na existência da burguesia desde as suas origens. (ALVES, 2007, p. 7980).

Ao analisar, historicamente, a constituição de uma matriz teórico-filosófica, nesse caso, o liberalismo, é importante destacar a perspicácia analítica de Marx e Engels (2007), ao escrever, na Ideologia Alemã, sobre a relação da consciência do homem e sua materialidade, que a produção de ideias e os pensamentos estão associados diretamente à forma de produzir materialmente a vida humana de cada tempo histórico.

A produção de ideias, de representações, da consciência, está, em princípio, imediatamente entrelaçada com a atividade material e com o intercâmbio material dos homens, com a linguagem da vida real. O representar, o pensar, o intercâmbio espiritual dos homens ainda aparecem, aqui, como emanação direta de seu comportamento material. (MARX e ENGELS, 2007, p. 93).

Com base no mesmo raciocínio, é possível entender as razões que levaram os liberais, ao final do século XIX e início do século XX, a ressignificar algumas de suas teses, particularmente no tocante à relação do indivíduo com o Estado. Para os liberais clássicos, a relação do indivíduo com o Estado é bem clara e determinada, cabe a este apenas assegurar a integridade física dos cidadãos contra agressões de qualquer natureza que coloquem em risco sua vida e, consequentemente, sua liberdade.

Os liberais acreditam, que dada a natureza humana, não é possível preservar a liberdade dos indivíduos sem um Estado que defenda o indivíduo contra violações de sua liberdade por outros indivíduos, e que se ocupe em defender a liberdade dos seus cidadãos contra agressões externas. Essas funções estatais, relacionadas com a proteção dos indivíduos uns contra os outros (função policial), com a arbitragem de desavenças (função judicial) e com a proteção dos indivíduos contra agressão externa (função militar), tudo isso com base em regras básicas e mínimas de convivência, são, portanto, para os liberais, necessárias e legítimas, indispensáveis para a preservação do máximo de liberdade possível para os indivíduos no ordenamento social. Sem um Estado que as desempenhe, os indivíduos ficarão presa fácil dos mais fortes ou mais espertos, tanto dentro como fora da comunidade em que vivem. (CHAVES, 2007, p. 39).

A leitura do contexto social, realizada pelos liberais no final do século XIX e início do século XX, aponta para os danos sociais provocados pela política econômica do laissez- 
faire, ou seja, uma política que coloca todos contra todos numa disputa desenfreada por um reservado lugar ao sol, provocando mais miséria, mais violência entre os indivíduos.

Concomitantemente a essa constatação da ineficácia da política liberal naqueles moldes, os "liberais sociais" tinham o receio de que essa situação pudesse alimentar uma grande revolta que colocaria em xeque todo o sistema de produção capitalista. Logo, a participação do Estado deveria ser colocada como sendo o agente responsável em manter a harmonia das relações conflituosas entre as classes sociais, de modo que suas políticas sociais garantissem o acesso das camadas populares aos benefícios mínimos produzidos pela "maravilhosa" máquina do capital.

Nesse sentido, a educação pensada por Dewey, adepto a nova forma de conceber o liberalismo, cumpriria um duplo papel, ambos essenciais para manter o ordenamento social. Num primeiro momento, a educação teria função de reorganização social, no sentido de trazer para si a responsabilidade moral de "remediar" as mazelas produzidas pelo capital, isto é,

[...] a função da educação é contribuir para recomposição das peças imperfeitas neste modelo. Entendida desta forma, ao invés de questionar o modelo social. Na organização hierárquica do trabalho na sociedade capitalista, a educação se colocaria no papel de reformadora e restauradora das mazelas que o próprio sistema capitalista proporcionou, entre as quais a marginalidade, a seletividade, a exclusão, as diferenças de oportunidades, as desigualdades sociais e o desemprego. (GALIANI, 2009, p. 44).

Num segundo momento, a educação é tida como referência para o desenvolvimento social e econômico de um país, pois um bom sistema, de ensino nacional, articulado com a ciência e tecnologia, garantia as condições necessárias para a superação do estado de miséria da população carente.

Portanto, a educação em Dewey passa a ter uma função socializadora no que se refere ao ensino e transformadora a partir dos conhecimentos ensinados. A sua proposta de reforma educacional deveria estar voltada não apenas para a educação e seu desenvolvimento, e sim para reformas na sociedade como um todo. (GALIANI, 2009, p. 45).

Com base nessa discussão sobre o contexto histórico e filosófico de Dewey, adentraremos na discussão mais detalhada sobre sua concepção de infância e como está associada ao contexto escolar, cultural e social.

\section{A centralidade da criança no projeto deweyano: uma visão de mundo}

Para tanto, o nosso trabalho buscou nas principais obras de Dewey seu conceito de infância, por vezes, de criança, pois ambos estão associados ${ }^{7}$. Dentre as diversas obras produzidas pelo autor, dedicamos mais atenção às obras relacionadas à educação, cultura, liberdade e experiência. As obras analisadas foram: Democracia e Educação: introdução à Filosofia da Educação de 1979; Experiência e educação de 1976; Liberdade e Cultura de 1953; Vida e Educação de $1978^{8}$.

Nesse momento, é fundamental discutir em qual contexto social e escolar Dewey discute, pois sua teoria se configura, ao mesmo tempo, como uma resposta contrária ao 
modelo educacional vigente e uma reafirmação dos valores e princípios morais do sistema capitalista ora em fase de consolidação mundial.

Para iniciarmos a discussão, é importante identificarmos a concepção de ser vivo concebida por Dewey para entendermos as raízes de sua crítica à escola tradicional e a defesa de uma escola que valorize o indivíduo. Segundo Dewey (1979), ser vivo "[...] é aquele que domina e regula em benefício de sua atividade incessante as energias que de outro modo o destruiriam. A vida é um processo que se renova a si mesmo por intermédio da ação sobre o meio ambiente". (DEWEY, 1979, p. 01).

Logo, o indivíduo, na perspectiva deweyana, é um sujeito mutável, em constante transformação, que participa do meio social, cujos interesses pessoais estão associados aos do seu grupo social, numa interação recíproca. Essa concepção de ser vivo, presente em Dewey, também é influenciada pela questão biológica, mormente pela teoria de Charles Darwin (1809-1882), defensor da teoria da evolução das espécies por meio da seleção natural, ou seja,

[...] a significação filosófica da doutrina da evolução reside principalmente em pôr em relevo a continuidade das formas orgânicas mais simples e mais complexas, até chegar-se ao homem. [...] O efeito disto sobre a teoria do conhecimento é afastar a noção de ser ela atividade de um mero observador ou espectador do mundo, noção essa que vai de par com a ideia de ser, o ato de conhecer, uma coisa por si mesma. (DEWEY, 1979, p. 370-371).

Para o historiador Schilling (2004), a teoria darwinista fornece aos pensadores liberais elementos fundamentais para justificar uma mudança nas relações sociais, pois "[...] o público leitor identificava-se com expressões como "luta pela sobrevivência", "seleção natural" ou ainda "vitória do mais apto", que bem traduziam a convivência no capitalismo". (SCHILLING, 2004, p. 91). Portanto, a ênfase no indivíduo em detrimento dos aspectos sociais é fundamentada numa perspectiva biológica ${ }^{9}$.

Com base nessa concepção de ser vivo, é possível avançarmos no entendimento sobre a discordância teórica do autor em relação aos preceitos defendidos pelo modelo da escola vigente de seu tempo. Para Dewey (1976), o sistema educacional carecia de reformas, uma vez que toda a sociedade passava por uma transformação geral, e o campo educacional precisaria acompanhar esse movimento, pois um modelo em que ensinar signifique transmitir "[...] um produto acabado, sem maior atenção quanto aos modos e meios por que originariamente assim se fez, nem também quanto às mudanças que seguramente irá sofrer no futuro" necessita de uma ampla reformulação. (DEWEY, 1976, p. 05-06).

Ao discutir a educação tradicional influenciada pelos princípios religiosos, temos a tendência em considerá-la restrita aos preceitos católicos, entretanto o confronto posto no contexto estadunidense da época de Dewey está marcado pela influência dos protestantes sobre o cenário escolar.

Diferente da postura católica em relação à divulgação do conhecimento, o protestantismo defende a liberdade do indivíduo, resguardado, primeiramente, a própria leitura do texto bíblico. De acordo com Karnal (2010), "Uma das origens da Reforma religiosa na Europa tinha sido a defesa da livre interpretação da Bíblia. [...] Essa preocupação levou a medidas bastante originais no contexto das colonizações da América". (KARNAL, 2010, p. 47-48). 
Segundo o autor, a educação nas 13 colônias tinha a preocupação de oferecer aos indivíduos o conhecimento das primeiras letras, com intuito de formar homens doutrinados na ordem religiosa protestante. Mas, conforme Karnal (2010),

É importante notar que os documentos sobre educação nas colônias inglesas apresentam um caráter religioso, mas não clerical. As propostas são, na verdade, leigas. A educação será feita e paga por membros da comunidade. [...] Em todos os documentos sobre educação, há a mesma preocupação: o conhecimento das coisas relativas à religião. Do ensino primário ao superior, o conhecimento da Bíblia parece ter orientado todo o projeto educacional das colônias inglesas. (KARNAL, 2010, p. 48-49, grifo do autor).

Apesar da preocupação em promover uma escolarização básica à população, não nos iludamos que essa postura expresse uma universalização do ensino. Conforme Karnal (2010), "[...] uma das regiões do mundo onde o índice de analfabetismo era dos mais baixos" e "[...] tinham um nível de educação formal bastante superior à realidade dos séculos XVII e XVIII, seja na Europa ou no restante da América" contrastava com uma realidade marcada pela divisão social do trabalho, pois, mesmo "[...] assim, é inegável que havia mais alfabetizados brancos homens e ricos do que mulheres, negros e indígenas pobres". (KARNAL, 2010, p. 50).

Portanto, o cenário escolar que está posto não condiz com os anseios de uma sociedade capitalista, por apresentar métodos e recursos antiquados que propiciem a formação de indivíduos livres, autônomos e participativos ${ }^{10}$. Para Marx e Engels (2010, p. 91), essa argumentação de cunho liberal, da necessidade de mudança no campo educacional, é uma espécie de camuflagem da real intenção dos capitalistas mais "humanistas", que se preocupavam com a educação.

Compartilhando desse sentimento humanista dos capitalistas, Dewey $(1979$, p. 130) reafirma a defesa da democracia como caminho para o progresso social, sendo que esse modelo educacional deve ser revisto e modificado. Como vem sendo discutido, a mudança do sistema de ensino extrapola a esfera escolar - métodos e conteúdos - e abrange outras esferas (econômica, política, cultural e social).

Por conseguinte, o confronto posto entre a educação vigente de seu tempo e as mudanças sociais forneceu, para o autor, as condições indispensáveis para a elaboração de um novo modelo educacional, em especial, uma nova ideia de infância, que rompesse com o estado de espírito estático e passivo e assumisse uma nova postura compromissada com o desenvolvimento econômico, social e político do país.

Para Valdemarin (2010), o compromisso de transformar a escola numa sociedade em miniatura configura um dos seus maiores desafios, pois a mudança deve atingir o plano administrativo-pedagógico, a relação professor e aluno e, sobretudo, garantir que a cultura seja "[...] apresentada de modo simplificado e acessível às diferentes faixas etárias e está depurada das contradições e problemas presentes na sociedade". (VALDEMARIN, 2010, p. 76).

O trecho anteriormente citado nos provoca uma indagação: por que depurar as contradições e problemas presentes na sociedade? Qual a intenção de depurá-las? É importante destacar que essa estratégia de divulgação e produção do conhecimento a partir dos aspectos da cultura local e trabalhar na resolução de situação-problema são artifícios utilizados para ocultar ao trabalhador, nesse caso, a criança e os adolescentes, as mediações essenciais para entender, por exemplo, o porquê de trabalhar coletivamente ou por que 
todos somos necessários para salvar o planeta [sic.]. Para Marx (2004), esse véu revestido sobre o trabalhador tem o objetivo de ocultar:

[...] o estranhamento na essência do trabalho porque não considera a relação imediata entre o trabalhador (o trabalho) e a produção. Sem dúvida. $\mathrm{O}$ trabalho produz maravilhas para os ricos, mas produz privação para o trabalhador. Produz palácios, mas cavernas para o trabalhador. Produz beleza, mas deformação para o trabalhador. Substitui o trabalho por máquinas, mas lança uma parte dos trabalhadores de volta a um trabalho bárbaro e faz da outra parte máquinas. Produz espírito, as produz imbecilidade, cretinismo para o trabalhador. (MARX, 2004, p. 82, grifo do autor).

Posto isto, identificamos o terreno social com o qual dialoga o autor e começamos a compreender sua razão para a defesa de uma nova educação, nova infância e nova escola. Portanto, indagamos: como foi pensada a infância nesse novo contexto social? A escola cumpre qual papel para formação dessa infância? A criança é vista como sujeito ou mero projeto social para o futuro?

A criança, na perspectiva deweyana, ganha centralidade não só no que se refere ao processo de ensino e aprendizagem, mas, numa óptica ampla, ela assume um papel protagonista para consolidação futura de uma nova sociedade. Segundo Dewey (1978), a criança:

[...] é o ponto de partida, o centro e o fim. Seu desenvolvimento e seu crescimento, o ideal. Só ele fornece a medida e o julgamento em educação. Todos os estudos se subordinam ao crescimento da criança: só têm valor quando sirvam às necessidades desse crescimento. [...] Aprender envolve um processo ativo de assimilação orgânica, iniciado internamente. De sorte que, literalmente, devemos partir da criança e nos dirigirmos por ela. [...]. (DEWEY, 1978, p. 46).

A escola tem um papel central na formação de uma nova infầncia, pois “[...] o progresso da civilização aumenta a distância entre a capacidade originária do imaturo e os ideais e costumes dos mais velhos. [...] A educação, e só a educação, suprime essa distância". (DEWEY, 1979, p. 03). Portanto, a escola é um dos meios pelos quais os indivíduos serão formados.

A realização da sociedade democrática está condicionada à questão da liberdade, educação e experiência do indivíduo e nos remete a pensar sobre a condição da criança, pois são os membros imaturos da sociedade que possuem o potencial da mudança. Entretanto Dewey (1979) ressalta que esse potencial na figura da criança não representa um desdenho em relação a sua fase em detrimento da posterior, pelo contrário, significa direcionar "[...] a atividade de seus membros mais novos, e determinando-lhes, por esse modo, o futuro, a sociedade determina o seu próprio". (DEWEY, 1979, p. 44).

Para melhor compreendermos essa relação, o conceito de experiência é de suma importância, pois nele o autor afirma o princípio da continuidade, isto é, o ser humano é aquilo que é nesse momento, fruto de suas experiências passadas e presentes, de modo que as situações futuras representam os interesses e desejos pessoais, influenciados pelo grupo social em que participa.

Segundo Dewey (1979), a experiência 
Em rigor significa $[. .$.$] um processo ativo prolonga-se no tempo e que seu$ período ulterior completa o período antecedente; projeta luz sobre as conexões nele implicadas mas até então despercebidas. O resultado final revela, assim, a significação do antecedente, ao passo que a experiência considerada como um todo estabelece uma determinada tendência ou disposição para com as coisas que possuam essa significação. Toda a experiência ou atividade assim contínua é educativa, e toda a educação consiste em ter tais experiências. (DEWEY, 1979, p. 85).

Para ilustrar melhor essa relação, Dewey (1979) explica a diferença de três palavras - direção, controle e guia, que podem ter sentidos próximos, porém com implicações distintas. Segundo o autor, o sentido de guiar está mais próximo do sentido da educação, pois "[...] a ideia de auxiliar, por meio da cooperação, as aptidões naturais dos indivíduos [...]" possibilita à escola explorar atividades que promovam o desenvolvimento e crescimento dos educandos. (DEWEY, 1979, p. 25).

Nesse sentido, é possível perceber que a ideia de criança, para o autor, está associada à liberdade e pró-atividade do indivíduo, pois o desenvolvimento e o crescimento da criança dependerão dessa relação, ou seja, não ocorrerá por uma imposição de hábitos e valores do adulto. Por outro lado, isso não quer dizer que a criança viva num mundo paralelo, separado do mundo do adulto com interesses próprios e distintos, mas que a incorporação dos hábitos e valores do grupo social tem que fazer sentido na vida das crianças, tem que pulsar em seus movimentos e fazê-las dispor de sua energia para compreendê-los e exercê-los.

O primeiro passo consiste em estabelecer condições que estimulem certos modos patentes e tangíveis de proceder; e o passo complementar é tornar de tal modo o indivíduo participante ou companheiro na atividade comum que ele sinta, como seus próprios, os triunfos e os maus êxitos da mesma. Desde que esteja possuído da atitude emocional do grupo, terá sempre o cuidado de procurar conhecer os fins especiais a que o referido grupo aspira e os meios necessários para garantir o triunfo. Por outras palavras suas crenças e ideais assumirão natureza análoga à dos demais de sua agremiação. E ele assumirá o cabedal de conhecimentos desta, uma vez que conhecê-los para o exercício da sua atividade habitual. (DEWEY, 1979, p. 15).

Portanto, Dewey (1979, p. 44-45) reafirma que a imaturidade da infância, comparada com as demais fases da vida humana, não significa incompletude ou imperfeição, pois, à medida que o processo de desenvolvimento ocorre por meio das experiências individuais ou em grupo, o crescimento acontece, dessa forma, o indivíduo acumula mais experiência e conhecimento, logo, é o processo de interação do indivíduo com a sociedade mediado pela experiência que determina seu crescimento e não a fase na qual esteja vivendo.

Dewey acredita que o processo desencadeado pela educação fundamentada na experiência e na liberdade do indivíduo traz um novo enfoque para o trabalho pedagógico, pois, nessa óptica, a centralidade está no aprendiz, seja ele criança, adolescente ou mesmo adulto, o importante é partir de seu interesse ${ }^{11}$ e promover o seu crescimento intelectual e moral. (DEWEY, 1976, p. 81-82). 


\section{Considerações finais}

É interessante observar que o trabalho pedagógico defendido na visão dos liberais se assemelha, em parte, com os anseios de uma educação voltada para a classe proletária, pois, para Marx e Engels (2010), a educação deve desenvolver os aspectos intelectual, corporal e tecnológico do homem, contudo a diferença aqui se encontra na perspectiva futura de sociedade, pois, para os liberais, a educação deve adequar-se às mudanças do contexto e evoluir, sempre que necessário, para manter essa "ordem natural" das coisas, isto é, a defesa incondicional da propriedade privada. Já na perspectiva comunista, “[...] o setor mais culto da classe operária compreende que o futuro de sua classe e, portanto, da humanidade, depende da formação da classe operária que há de vir". (MARX e ENGELS, 2010, p. 69).

Para Marx e Engels (2007), a semelhança entre os objetivos é prolongável até o determinado momento em que a classe dominante "[...] é obrigada, para atingir seus fins, a apresentar seu interesse como o interesse comum de todos os membros da sociedade, [...] é obrigada a dar às suas ideias a forma da universalidade, a apresentá-las como as únicas racionais, universalmente válidas". (MARX e ENGELS, 2010, p. 48).

Logo, concluímos o porquê da preocupação do movimento escolanovista em incorporar princípios que comungam vários grupos e tendências em prol da reformulação pedagógica, pois sua intenção principal é "[...] entre outras coisas, que eles dominem também como pensadores, como produtores de ideias, que regulem a produção e a distribuição das ideias de seu tempo; e, por conseguinte, que suas ideias sejam as ideias dominantes da época". (MARX e ENGELS, 2010, p. 47).

Com esse entendimento, Dewey (1979) considera a criança o protagonista dessa renovação pedagógica por duas razões: a primeira, por ser um sujeito imaturo e inexperiente, e a segunda, por ter a capacidade de desenvolvimento e crescimento.

[...] capacidade, uma aptidão, um poder; [...] energia, força. Ora, quando dizemos que imaturidade significa a possibilidade de crescimento, não nos referimos à ausência de aptidões que poderão surgir mais tarde; referimo-nos a uma força atual - a capacidade $e$ aptidão para desenvolver-se. (DEWEY, 1979, p. 44, grifo nosso).

É possível perceber, claramente, a concepção de infância do autor, isto é, a infância, na perspectiva deweyana, é pensada a partir da relação da experiência com o meio social e sua potencialidade de mudança, algo que contribui decisivamente para realização de uma sociedade democrática.

Portanto, percebemos que a concepção de infância em Dewey (1979, p. 53-54) coloca a criança no centro do processo educativo e social, isto é, por meio das experiências infantis, é possível ampliar seu estado cognitivo, emocional, cultural e político, e, ao final desse processo, o propósito é formar homens com capacidade de liderança, espírito participativo e talento criativo na resolução de situações-problemas do cotidiano.

O propósito almejado pelo filósofo nos desafia a pensar a realização dessa nova concepção. A liberdade, a democracia e a experiência livre do educando são possíveis dentro de uma sociedade determinada pelas condições materiais desiguais? Ou melhor, é possível para qual classe social?

Nessas circunstâncias, vale ressaltar que nos deparamos com uma concepção de mundo, de sociedade e de homem em que, para nós, é inviável a realização plena de tais 
atividades. Segundo Kosic (1976), o sistema capitalista opera um mecanismo que transfigura a realidade concreta para uma realidade abstrata, isto é, projeta "[...] na consciência do sujeito, de determinadas condições históricas petrificadas". (KOSIC, 1976, p. 15 , grifo do autor).

Logo, acreditamos que somente uma transformação nas relações sociais tornaria viável a concretização da liberdade e da democracia. Isto quer dizer que, uma sociedade sem exploração do trabalho alheio para fins privados, de acumulação de capital, uma associação livre dos homens em que o princípio do trabalho coletivo seja extraído das reais necessidades humanas.

Para Marx e Engels (2010), a realização da sociedade comunista será obra dos próprios trabalhadores organizados em classe, fruto de sua luta histórica contra a exploração do trabalho. Logo, como consequência dessa ação política, “[...] desaparecerá toda a diferença de classe. Por isso, a sociedade organizada segundo o modo comunista é incompatível com a existência de classes sociais e oferece diretamente os meios para eliminar tais diferenças de classe". (MARX e ENGELS, 2010, 106).

\section{Referências}

ARAÚJO, J. C. S. Marcos filosóficos da modernidade em torno da educação da criança: antropologias da infância em disputa? In: MOURA, E. B. B. de., CARVALHO, C. H. de., ARAÚJO, J. C. S. (org.). A infância na modernidade: entre a educação e o trabalho. Uberlândia: Edufu, 2007. p. 179-207.

ALVES, G. L. O liberalismo e a produção da escola pública moderna. In: LOMBARDI, J. C., SANFELICE, J. L. (orgs.) Liberalismo e educação em debate. Campinas: Autores Associados, Histedbr, 2007. p. 61-86.

ASSOCIAÇÃO BRASILEIRA DE NORMAS TÉCNICAS. NBR 6023: 2002 Informação e documentação - Referências - Elaboração.

CAMBI, F. História da Pedagogia. Tradução de Álvaro Lorencini. São Paulo: Editora UNESP, 1999.

CHAVES, E. O. C. O liberalismo na política, econômica e sociedade e suas implicações para a educação: uma defesa. In: LOMBARDI, J. C., SANFELICE, J. L. (orgs.). Liberalismo e educação em debate. Campinas: Autores Associados, Histedbr, 2007. p. 01-60.

DEWEY, J. Liberdade e Cultura. Tradução e introdução de Eustáquio Duarte. [S.I.]: Revista Branca. 1953.

Experiência e educação. Tradução de Anísio Teixeira. $2^{a}$ ed. São Paulo: Ed. Nacional. 1976.

Vida e educação. Tradução e estudo preliminar por Anísio Teixeira. $10^{\mathrm{a}}$ ed. São

Paulo: Melhoramentos; Rio de Janeiro: Fundação Nacional de Material Escolar, 1978.

Democracia e educação: introdução à Filosofia da Educação. Tradução de Godofredo Rangel e Anísio Teixeira. 4ª ed. São Paulo: Companhia Editora Nacional. 1979.

DUARTE, N. Concepções afirmativas e negativas sobre o ato de ensinar. Cad. CEDES, Campinas, v. 19, n. 44, abr. 1998. Disponível em http://www.scielo.br/scielo.php?script=sci_arttext\&pid=S0101-

2621998000100008\&lng=pt\&nrm=iso>. Acessos em 18 out. 2011. http://dx.doi.org/10.1590/S0101-32621998000100008. 

2004.

(org.). Crítica ao fetichismo da individualidade. Campinas: Autores Associados,

Sobre o construtivismo: contribuições a uma análise crítica. Campinas: Autores Associados, 2005.

. Vigotski e o "aprender a aprender": crítica às apropriações neoliberais e pósmodernas da teoria vigotskiana. $4^{\mathrm{a}}$ ed. Campinas: Autores Associados, 2006.

GALIANI, C. Educação e democracia em John Dewey. Maringá: Eduem, 2009.

HOBSBAWM, E. J. A era do capital - 1848-1875. Tradução de Luciano Costa Neto. Rio de Janeiro: Paz e Terra. 1977.

JEFFERSON, T. Escritos políticos. Tradução de Leônidas Gontijo de Carvalho. São Paulo: IBRASA, 1964.

KARNAL, L. [et al]. História dos Estados Unidos: das origens ao século XXI. $2^{\text {a }}$ ed. São Paulo: Contexto, 2010.

KOSIC, K. Dialética do concreto. RJ: Paz e Terra, 1976. p. 07-54.

MANACORDA, M. A. História da Educação: da antiguidade aos nossos dias. $13^{\mathrm{a}}$ ed. Tradução de Gaetanto Lo Monaco. São Paulo: Cortez, 2010.

MARX, K. Manuscritos econômico-filosóficos. $1^{\text {a }}$ ed. Tradução e notas de Jesus Ranieri. São Paulo: Boitempo, 2004.

MARX, K., ENGELS, F. A ideologia alemã: crítica da mais recente filosofia alemã em seus em seus representantes Feuerbach, B. Bauer e Stirner, e do socialismo alemão em seus diferentes profetas (1845-1846). Tradução de Rubens Enderle, Nélio Shneider e Luciano Cavini Martorano. São Paulo: Boitempo, 2007. p. 25-95.

. Textos sobre educação e ensino. Campinas: FE/ Unicamp - Navegando Publicações, 2010.

PEIRCE, C. S. Semiótica. Tradução de José Teixeira Coelho Neto. $4^{\mathrm{a}}$ ed. São Paulo: Perspectiva. 2008.

SAVIANI, D. Pedagogia histórico-crítica: primeiras aproximações. 10 ed. Campinas: Autores Associados, 2008.

SCHILLING, V. América: a história e as contradições do império. Porto Alegre: L\&PM, 2004.

VALDEMARIN, V. T. História dos métodos e materiais de ensino: a escola nova e seus modos de uso. São Paulo: Cortez, 2010.

Notas

1 Este artigo é parte de uma pesquisa de mestrado que resultou na dissertação intitulada $A$ concepção de Infância presente no Manifesto dos Pioneiros da Educação Nova de 1932: a presença do pensamento de John Dewey (1859-1952), que contou com o financiamento da Capes sob forma de bolsa de mestrado.

2 Segundo Dewey (1953, p. 150-151), “[...] os fundadores da democracia americana, as reivindicações democráticas eram, inerentemente, reivindicações de uma moral justa e igual. [...] Por isso mesmo, a tarefa dos que têm fé na democracia é reviver e manter em pleno vigor a convicção original acerca de sua intrínseca natureza moral, exposta agora de forma congruente com as atuais condições de cultura. Temos 
avançado o bastante para dizer que a democracia é um estilo de vida. Teremos, contudo, de mostrar que ela é um estilo pessoal de vida; e que de fato provê um padrão moral para toda a nossa conduta".

3 Afirmamos que o homem é um produto histórico do seu contexto por acreditar que sua formação está condicionada aos meios materiais de sua produção, logo, "[...] o que eles são coincide, pois, com sua produção, tanto com o que produzem como também com o modo como produzem. O que os indivíduos são, portanto, depende das condições materiais de sua produção". (MARX, ENGELS, 2007, p. 87, grifo do autor).

4 Neste ponto, é importante mencionar que o "caráter liberal" não é um entendimento homogêneo para todos os liberais. Para Chaves (2007, p. 33), o liberalismo não pode sofrer qualquer intervenção externa que oprima a individualidade do ser humano, isto é, o indivíduo deve ser livre para tomar qualquer iniciativa, e nem por isso "[...] o liberalismo não é, nem de longe, insensível aos problemas sociais e defende todas as iniciativas feitas para resolvê-los que envolvam a participação voluntária das pessoas. O liberalismo opõe-se a que o governo procure solucionar esses problemas, fundamentalmente, porque, quando o governo intervém, ele obriga, pelo uso da força ou pela ameaça do uso da força, as pessoas a contribuír com ele, mesmo contra a sua vontade, violando assim a sua liberdade e o seu direito à sua propriedade (recursos financeiros)". Como podemos observar, a defesa do autor sobre o liberalismo será alvo de críticas de outros liberais que defendem, mesmo que mínima, a participação estatal na área social para garantir condições básicas de convivência harmônica entre as diferentes classes sociais, dentre eles, Dewey. Segundo Galiani (2009, p. 141), ele "[...] posicionou-se contra o individualismo liberal e acusou os liberais por explicarem as diferenças sociais como sendo resultado das diferenças individuais, assim, o fracasso e o sucesso dependeria de cada indivíduo. Entretanto, no seu discurso, ele não abandona certos pressupostos liberais, ao contrário, busca uma significação coletiva para pressupostos como: o individualismo, a liberdade, a democracia e a solidariedade. Isso permite concluir que, mesmo com posicionamentos diferentes, o discurso que predomina é o da classe burguesa, e as questões que se constituem eixo de preocupação deste autor são as da classe burguesa e, do encaminhamento dado ao tratamento dessas questões, dependeria a sua continuidade hegemônica ou a sua eliminação. Por essa razão, infere-se que suas propostas não eram revolucionárias, mas apenas inovadoras".

5 Para Marx (2004, p. 80, grifo do autor), "O trabalhador se torna tanto mais pobre quanto mais riqueza produz quanto mais a sua produção aumenta em poder e extensão. $\mathrm{O}$ trabalhador se torna uma mercadoria tão mais barata quanto mais mercadorias cria. Com a valorização do mundo das coisas (Sachenwelt) aumenta em proporção direta a desvalorização do mundo dos homens (Menschenwelt). O trabalho não produz somente mercadorias; ele produz a si mesmo e ao trabalhador como uma mercadoria, e isto uma vez que produz, de fato, mercadorias em geral".

6 A utilização do termo "liberais sociais" pode parecer estranha, e, em certa medida, é, mas cabe a distinção por entender que o pensamento liberal ao longo da história sofreu algumas modificações, todas elas com o mesmo objetivo, manter a ordem social e econômica nos padrões estabelecidos pela burguesia. A adjetivação social está sendo empregada no sentido dado pelos liberais à época de tratar as questões sociais (educação, saúde, cultura, habitação etc.) como algo que necessitaria de uma intervenção maior do Estado com duas intenções claras: a primeira, na formulação e execução de políticas sociais que amenizassem as desigualdades sociais e econômicas produzidas pelo sistema de produção capitalista; a segunda, afastar e desacreditar das ideias de outra sociedade que não seja a capitalista. Dentre os "liberais sociais", podemos identificar Dewey como um dos quais percebem a necessidade de mudar a forma e o agir na sociedade. De acordo com Galiani (2009, p. 143, grifo do autor), "O contexto social que determinou as bases do pensamento de Dewey acentua este papel do Estado que a um só tempo promove a ampliação das desigualdades, ao permitir os investimentos na produção capitalista, sem interferência, mas, ao perceber que a ampliação das desigualdades ameaçavam a própria ordem burguesa, estabelece uma reformulação política, nos moldes do new deal, como um meio de proporcionar o equilíbrio nas relações econômicas, com medidas intervencionistas, assim, permite recompor e conservar a ordem burguesa no país".

7 Neste artigo, entendemos o termo infância e criança na perspectiva adotada por ARAÚJO (2007). Segundo o autor, "A infância é uma etapa da vida. Assim como são as fases da vida a adolescência, a juventude, a adultícia e a velhice. $\mathrm{O}$ termo criança se refere concretamente à pessoa que está vivendo a infância". (ARAÚJO, 2007, p. 186, grifo do autor). Logo, "Infância, etimologicamente, vem do verbo fari - que significa falar, ter a faculdade e o uso da fala; daí a derivação como infans, antis (que não fala; que tem pouca idade, infantil, criança). Portanto, infantia significa dificuldade ou incapacidade de falar, nudez. 
Já o terno criança tem sua etimologia vinculada ao verbo criar + anca, que significa o indivíduo na infância". (ARAÚJO, 2007, p. 189, grifo do autor).

8

DEWEY, J. Democracia e educação: introdução à Filosofia da Educação. Tradução de Godofredo Rangel e Anísio Teixeira. $4^{\mathrm{a}}$ ed. São Paulo: Companhia Editora Nacional. 1979. Publicação dos originais: (Democracy and Education: An Introduction to the Philosophy of Education (New York: Macmillan, 1916; New York: Free Press / London: Collier-Macmillan, 1944).

DEWEY, J. Experiência e educação. Tradução de Anísio Teixeira. $2^{a}$ ed. São Paulo: Ed. Nacional. 1976. Publicação dos originais: Experience and Education (London \& New York: Macmillan, 1938).

DEWEY, J. Liberdade e Cultura. Tradução e introdução de Eustáquio Duarte. [S.I.]: Revista Branca. 1953. Publicação dos originais: Freedom and Culture (New York: Putnam, 1939; London: Allen \& Unwin, 1940).

DEWEY, J. Vida e educação. Tradução e estudo preliminar por Anísio Teixeira das obras: A criança e o programa escolar e Interesse e esforço em educação (Interest and Effort in Education (Boston: Houghton Mifflin, 1913; Bath, U.K.: Chivers, 1969).10ª ed. São Paulo: Melhoramentos; Rio de Janeiro: Fundação Nacional de Material Escolar, 1978.

9 Duarte (2006) analisa como a burguesia apropria-se do discurso evolucionista em prol da sua perpetuação no poder de forma a cristalizar o discurso da seleção natural, ou seja, sempre foi assim ao longo da história humana, uns vencem ou perdem. "A sociedade burguesa produz a concepção de que a luta entre os indivíduos é própria da natureza humana e, nessa luta, cada indivíduo persegue seus interesses particulares. Surge assim a concepção de que o desenvolvimento tanto do gênero humano de cada indivíduo é fruto dessa constante tensão entre individualismo e convivência social. Aquilo que é uma característica específica à organização social capitalista é universalizado, no plano ideológico, a toda a história humana, transformando a competição própria da sociedade mercantil em algo natural ao ser humano em toda e qualquer época". (DUARTE, 2006, p. 137).

10 Apesar da postura autoritária e dogmática da educação mantida pelos protestantes nos Estados Unidos, vivemos numa sociedade contraditória, em que o novo e o velho se entrecruzam. Uma amostra disso é o estudo realizado por WEBER, M. A ética protestante e o espírito do capitalismo. $2^{\mathrm{a}}$ ed. Tradução de M. Irene de Q. F. Szmrecsanyi, T. J. M. K. Szmrecsanyi. São Paulo: Pioneira, 2001. O sociólogo alemão apresenta, em sua obra, uma relação explícita entre os princípios religiosos do protestantismo com os ideais burgueses. Ver com mais atenção os capítulos II e IV da referida obra.

11 No entendimento deweyano, "Interesse é, primeiro, qualquer coisa de ativo ou propulsivo - nós tomamos interesse, isto é, tomamos impulso, empenhamo-nos ativamente nisto ou naquilo. Em interesse, não há simplesmente um sentimento inerte ou passivo, mas alguma coisa de motriz, de dinâmico. Em segundo lugar, interesse é objetivo. Dizemos: Fulano tem muitos interesses de que tratar. Comentamos a extensão dos seus interesses - comerciais, locais, etc. identificamos interesses a negócios. Interesses, assim, são sempre concretizados em alguma coisa, não se confundindo com simples sentimentos. Em terceiro lugar, ainda, o interesse é pessoal. Significa que estamos diretamente ligados a alguma coisa que tenha importância para nós. Por isso, além dos seus aspectos de atividade e de objetividade, tem um aspecto emocional e pessoal". (DEWEY, 1978, p. 71, grifo do autor).

Recebido em maio/2012

Aprovado em novembro/2012 